\title{
Diversidade sexual, relações de gênero e políticas públicas
}

\section{Diversidade sexual, relações de gênero e políticas públicas.}

NARDI, H. C.; SILVEIRA, R. S.; MACHADO, P. S. (Org.).

\author{
Porto Alegre: Sulina, 2013. 207 p.
}

Os autores e organizadores do livro possuem formação na área de ciências da saúde Medicina, Educação Física, Psicologia - e também em Estatística e Artes Visuais. Apesar dessa diferença, todos fazem parte de grupos de pesquisas relacionados aos estudos de direitos humanos, diversidade sexual e de gênero, ligados às instituições de ensino: Universidade Federal do Rio Grande do Sul (UFRGS) e Universidade Federal de Santa Catarina (UFSC).

O livro Diversidade sexual, relações de gênero e políticas públicas está estruturado da seguinte forma: a primeira parte focaliza os movimentos sociais na busca por direitos igualitários; a segunda parte apresenta os estudos realizados pelo Núcleo de Pesquisa em Sexualidade e Relações de Gênero (NUPSEX), da UFRGS; e, no terceiro bloco, intitulado "Anexos", apresenta a parentalidade e conjugalidade de casais de pessoas do mesmo sexo e também a legislação sobre igualdade de direitos.

Na apresentação, os organizadores enfatizam a interdisciplinaridade da obra e também apresentam a sua utilidade: servir como ferramenta de formação de profissionais para atuação nas políticas públicas. No desfecho, os organizadores informam que o livro originou-se do trabalho conjunto entre o grupo NUPSEX e o Centro de Referência em Direitos Humanos, Relações de Gênero e Sexualidade, ambos vinculados ao programa de Pós-Graduação em Psicologia Social e Institucional e ao Instituto de Psicologia da UFRGS.
No primeiro texto, "Relações de Ggnero e diversidade sexual: compreendendo o contexto sociopolítico contemporâneo", de Henrique Nardi, faz-se um resgate histórico do conceito de homossexualidade e de seus marcos, como a retirada da homossexualidade do rol de doenças da Associação Psiquiátrica Norte-Americana, a revolta de Stonewall, em Nova lorque - que originou os movimentos Lésbicas, Gays, Bissexuais e Travestis/Transexuais (LGBT). O autor aborda, ainda, questões relacionadas à homofobia, ao heterossexismo, à heteronormatividade, à heterossexualidade compulsória, além de questões relacionadas à epidemia de AIDS, assim como aos movimentos sociais e à legislação. No desfecho, são apresentados alguns elementos para luta contra o preconceito.

O texto "Sobre travestilidades e políticas públicas: como se produzem os sujeitos", de Maria Filgueiras e Marília Amaral, apresenta dados relacionados à violência contra os homossexuais e às formas de opressão, nos diversos contextos em que transitam: família, escola e trabalho. Aborda questões acerca do projeto "Direitos e violências na experiência de travestis e transexuais em Santa Catarina: construção de perfil psicossocial e mapeamento de vulnerabilidades" - o qual visa oferecer subsídios de inclusão social a esses sujeitos -, assim como outras questões relacionadas a políticas públicas.

Em "'Senhora, essa identidade não é sua!': reflexões sobre a transnomeação", de Camila Guaranha e Eduardo Lomando, é apresentado o nome enquanto signo importante nas questões individuais e sociais para travestis, transexuais e demais casos relacionados; os autores afirmam que o nome social é o ponto-chave para construção de novas identidades.

No capítulo "Ser trans e as interlocuções com a educação", de Marina Reidel, é apresentada uma reflexão sobre os direitos do movimento trans, composto por travestis e transexuais. É destacado que, mesmo com os recentes avan- 
ços, como a criação da Articulação Nacional de Travestis e Transexuais (ANTRA), ainda há muito a ser discutido e realizado no que diz respeito à inserção política, social e educacional, desse grupo.

No texto "Da patologia à cidadania", de Célio Golin, são destacadas questões para reflexão sobre o movimento de gays, lésbicas, travestis e transexuais. No decorrer do texto, o autor apresenta relatos do grupo no qual é coordenador Nuances -, que atua no movimento pela livre expressão sexual.

Em "Nuances de uma in(ter)venção indisciplinada com gênero e sexualidade: vertigens de um modo de fazer políica", de Fernando Pocahy, o autor apresenta experiências de pesquisa e atuação junto ao grupo Nuances, trazendo a história local (Porto Alegre-RS) dos movimentos da população de Lésbicas, Gays, Bissexuais, Transgênero/Transexual, Intersexual (LGBTI), destacando os marcos: Parada livre (1997), associação com a Assessoria Jurídica e Estudos de Gênero (Themis) (2001), Projeto Olhares (2004), dentre outras atividades.

O capítulo "Violência doméstica contra as mulheres e a Lei Maria da Penha: uma discussão que exige reflexão e formação permanentes", de Raquel Silveira e Henrique Nardi, traz dados estatísticos da violência contra a mulher, além das medidas de prevenção e redes de proteção contra esse tipo de violência. Esse texto, segundo seus autores, objetiva servir de incentivo à reflexão para os profissionais que atuam no atendimento a esse público.

Em "A mulher-mãe e o homem-ausente: notas sobre feminilidades e masculinidades nos documentos das políticas de assistência social", de Priscila Detoni e Lucas Goulart, os autores apresentam as políticas públicas assistenciais, no âmbito federal, no que se refere às suas ações. O texto ainda discute o papel da mulher na sociedade e faz uma crítica ao papel da mulher como "reprodutora".

O primeiro texto da segunda parte, intitulado "Diversidade sexual e discriminação: ética e estética", de Cristina Moraes, faz um relato sobre a aplicação da oficina de mesmo título, apresentado no XII Salão de Extensão da UFRGS, em 2012.

O segundo, "Homofobia no contexto escolar: vivências de uma observação participante", de Rodrigo Peroni e Julia Rombaldi, traz o relato sobre a pesquisa "Formas de enfrentamento da homofobia nas escolas: análise de projetos em andamento na regiáo metropolitana de Porto Alegre", iniciada em 2011 e que se encontrava em andamento quando o capítulo foi escrito.

No capítulo "Mapeamento da rede de atenção em direitos humanos, relações de gênero e sexualidade", de Priscila Detoni, Daniela Bassanesi e Vinícius Roglio, apresenta-se a atuação do Centro de referência em Direitos Humanos, Relações de Gênero e Sexualidade (CRDH), projeto ligado à UFRGS e com objetivo de assistir mulheres e público LGBT no que concerne aos diversos tipos de violência.

O anexo "Estado de arte da pesquisa a respeito da parentalidade e conjugalidade de casais de pessoas do mesmo sexo a partir do "amici curiae do defense of marriage act" é uma tradução, feita por Ângelo Costa, do relatório da APA sobre a Lei de defesa do casamento nos EUA. O autor dessa tradução, no anexo "Síntese de políticas LGBTIS nacionais, estaduais e locais", apresenta uma coletânea de leis (federais, estaduais - Rio Grande do Sul - e municipais Porto Alegre) sobre igualdade de direitos no campo da diversidade sexual.

De um modo geral, o livro apresenta uma crítica tanto da ideia de superioridade masculina quanto da imposição linguística de gênero, que pode ser evidenciada no texto de Henrique Nardi, no momento em que o autor opta por utilizar o símbolo “@” (arroba), ao invés de "o" ou "a", para referir-se simultaneamente a ambos os gêneros, colocando-os em situação de igualdade; ou, ainda, no uso da expressão "guei", ao invés da usual "gay", no texto de Célio Golin. Nesta passagem, percebe-se uma tentativa de "aportuguesar" esse termo, buscando identidade própria dentro do contexto em que se está inserido.

O livro traz temas atuais e relevantes tanto para o público LGBT quanto para pesquisadores e pessoas que atuam nessa área, apresentando diversas vertentes, como os Direitos Humanos, a Legislação, a Educação, entre outros aspectos, cumprindo a abordagem interdisciplinar com a qual a obra compromete-se em sua apresentação.

Portanto, ainda que algumas passagens tenham carecido de bases teóricas mais aprofundadas, o livro se mostrou de extrema importância, por apresentar conteúdos que podem servir de subsídio para pesquisas nas áreas de relações de gênero e diversidade sexual.

Deise Parula Munhoz Universidade Federal do Rio Grande 